\title{
INFLUENCE OF THE RIVER OTTER (LONTRA CANADENSIS) ON THE FORMATION OF PRO-CONSERVATION INTENTIONS IN THE GREATER YELLOWSTONE ECOSYSTEM
}

\author{
KELLY J. PEARCE $\uparrow$ UNIVERSITY OF MARYLAND \\ CENTER FOR ENVIRONMENTAL SCIENCE \ FROSTBURG, MD \\ TOM L. SERFASS $\uparrow$ FROSTBURG STATE UNIVERSITY $\downarrow$ FROSTBURG, MD
}

\begin{abstract}
$\downarrow \quad$ ABSTRACT
The potential to increase participation in support and fundraising, as well as affect proconservation intentions and behaviors makes the flagship approach valuable to conservation. Flagships are charismatic species that engender public interest and promote broader ecological and economic values of conservation. Advocates for wildlife tourism suggest that viewing flagships can increase tourists' awareness and participation in conservation behaviors such as philanthropy, volunteering and activism. However, empirical support for behavioral outcomes associated with flagship exposure is lacking. Exposure to a flagship can vary, such as exposure to marketing materials (i.e., websites, guide books, environmental organizations) or direct viewing experience (i.e., wild, captive). The specific goal of this study was to: (a) determine if direct exposure to the river otter, or marketing material about the species and/or (b) a person's level of environmental concern influences behavioral intentions to conserve the river otter and its habitat. On-site self-administered questionnaires ( $n$ $=523$ ) were conducted at 6 locations throughout the Greater Yellowstone Ecosystem (GYE) from 5 June 2015 to 24 August 2015. The results of this study suggests that exposure to the river otter heightens concern and can lead to the formation of specific environmental intentions such as keeping local waterways unpolluted and planting trees along local waterways.
\end{abstract}

\section{$\downarrow \quad$ INTRODUCTION}

\begin{abstract}
Governmental and private conservation organizations often use flagship species (ambassadorial species that act as rallying points to stimulate conservation awareness and action [Dietz et al. 1999]) to achieve conservation goals. The ability of flagship species to raise awareness, increase knowledge and trigger behavioral changes makes this approach valuable to conservation campaigns, especially during this time of large-scale environmental concerns (Smith and Sutton 2008, Skibins and Powell 2013). Advocates for wildlife tourism suggest that viewing flagships can increase tourists' awareness and participation in conservation behaviors such as philanthropy, volunteering and activism (Smith and Sutton 2008). However, empirical support for behavioral outcomes associated with flagship exposure is lacking.
\end{abstract}

The river otter (Lontra canadensis), a top aquatic predator, has many physical, behavioral and ecological attributes indicative of a flagship species. For example, the river otter has been popularized through media portrayals as being charismatic, cute, and playful. Such portrayals engender public support, interest and awareness of the river otter, which contribute to enhanced recognition that the species has an obligate dependence on healthy aquatic environments.

A variety of aquatic systems exist in the Greater Yellowstone Ecosystem (GYE), which provide undisturbed habitat to the river otter and other charismatic wildlife. GYE, a popular wildlife tourism destination, encompasses both Yellowstone (YELL) 
and Grand Teton National Park (GRTE), and is an ideal location to evaluate the ability of the river otter to act as a flagships species by assessing the willingness of visitors to engage in aquatic conservation behaviors such as planting trees along local waterways, spending time to keep rivers and streams unpolluted, or making a financial contribution to river otter habitat conservation.

The results presented here are part of a larger project to investigate the potential of the river otter (Lontra canadensis) to serve as an aquatic flagship for the Greater Yellowstone Ecosystem. The primary objective of this study was to determine visitor attitudes towards the environment and the river otter, and assess if different direct exposure types to the river otter (i.e., observing the river otter in wild or in captivity), or indirect exposure to marketing materials about the species influences behavioral intentions to conserve the river otter and its habitat.

\section{$\uparrow \quad$ METHODS}

\section{Data collection}

On-site self-administered questionnaires were conducted at 6 locations throughout the GYE, including Trout Lake in YELL, 2 fishing access locations on the Madison River, 2 fishing access locations on the Yellowstone River, and 1 fishing access location on the Snake River (Figure 1). The goal of the questionnaire was to survey both general visitors and visitors who were engaged in fishing activities (i.e., anglers). Researchers administered surveys to visitors $(n=523)$ from 5 June 2015 to 24 August 2015 visitors. An intercept sampling method was used for survey-data collection and efforts were made to ask every visitor (over the age of 18) encountered to take the survey (Davis et al. 2012). The questionnaire was designed to assess 1) sociodemographic factors such as age, education, residency, and income, 2) level of concern for the river otter, its habitat, and the environment in general, 3) willingness to participate in pro-conservation behaviors, and 4) exposure to the river otter and its habitat. Five hundred and twenty-three surveys were completed, with a response rate of $81 \%$.

Visitor intentions to conserve the river otter and/or its habitat, specific and general environmental concern variables were collected by asking them to rank their level of agreement with various statements on a 5-point Likert scale, ranging from " 1 , strongly disagree," to "3, neutral," to "5, strongly agree." These statements were designed to address a variety of actions people could take to protect the river otter and its environment, and general and specific environmental concerns. Some of the survey statements were based on a previous study on flagships by Smith and Sutton (2008).

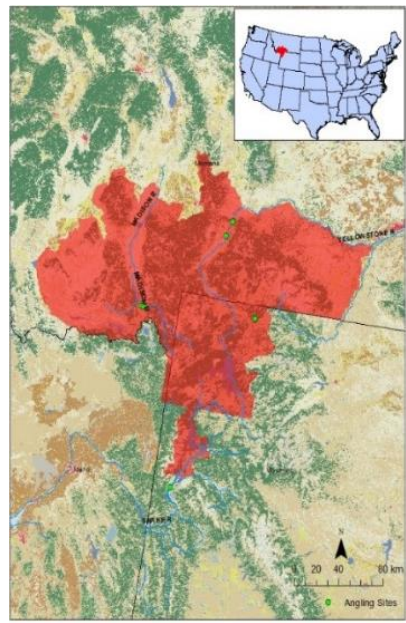

Figure 1. On-site self-administered questionnaires were conducted from 5 June 2015 to 24 August 2015 at 6 locations in the Greater Yellowstone Ecosystem, United States.

\section{Data analysis}

Descriptive statistics were used to summarize socio-demographic characteristics, and other closedended survey questions. A series of logistic regression analyses were used to test the effects of exposure and environmental concern variables on the probability of having intentions to conserve the river otter and its habitat (Figure 2). Prior to analysis, the ordinal measures of general and specific environmental concern and intentions were transformed into dichotomous variables - a score of 3 or less was recorded to represent "no intention" and a score of 4 or 5 were recorded to represent "intention" or "environmentally concerned."

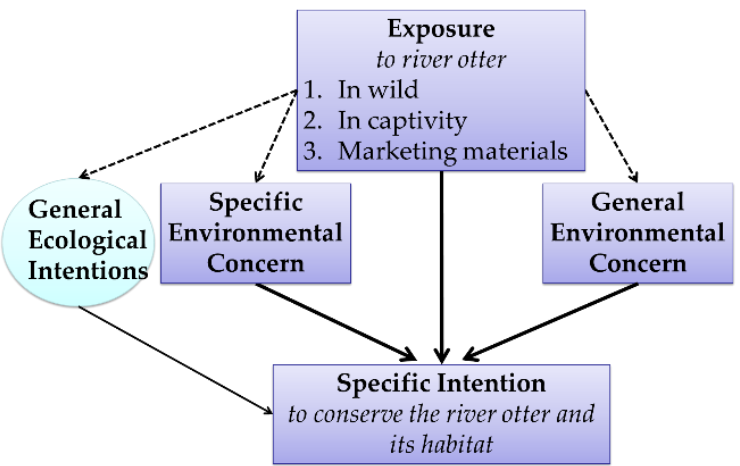

Figure 2. Pathway of analysis for determining the relationship between exposure, environmental concern, and intention. Bold solid arrows represent the primary path; dotted arrows are the secondary path, and the solid thin arrows indicate control for general ecological intentions. (Based on a conceptual framework by Smith and Sutton [2008]). 


\section{$\uparrow \quad$ PRELIMINARY RESUltS}

Most visitors held an Associate's degree or higher $(n=406)$ and the average age of participants was $46( \pm 0.70 \mathrm{SE})$ (Table 1$)$. Most people $(n=311$, $68 \%$ ) of respondents were classified as having intentions to engage in ecological behaviors, and 53\% ( $n=217)$ were classified as having intentions to conserve the river otter and its habitat. Seventy-two percent of participants $(n=378)$ indicated they had previously viewed a river otter in the wild or in captivity (Figure 3 ). Some visitors $(n=175,33 \%)$ were previously exposed to river otter marketing materials (i.e., a guidebook, NPS brochure or website, National Wildlife Federation website, Yellowstone Association website/visitor center) that described some natural history of the river otter and its associated habitat (Figure 3).

General environmental concern, and general ecological intentions were determined to influence intentions to conserve the river otter and its habitat (Table 2). Only 1 of the exposure effects tested was significant. The odds of an individual being specifically concerned about the river otter and its habitat increased 1.87 times with exposure to marketing materials about the river otter.

Table 1. Socio-demographic characteristics of visitors surveyed ( $n=517$ ) from 5 June 2015 to 24 August 2015 at 6 locations throughout the Greater Yellowstone Ecosystem.

\begin{tabular}{lll}
\hline Characteristic & Frequency & Percent \\
\hline \hline Gender & & \\
Male & 300 & 58 \\
Female & 217 & 42 \\
Education & & \\
$\quad$ Some High School or less & 3 & $<1$ \\
High School Diploma & 34 & 7 \\
Some College & 61 & 12 \\
Associates or Bachelor & 190 & 37 \\
Some Graduate & 43 & 9 \\
Graduate Degree & 173 & 34 \\
Income & & \\
S24,999 & 28 & 6 \\
25,000 74,999 & 131 & 26 \\
$75,000 \leq 124,999$ & 114 & 23 \\
125,000 $\leq 174,999$ & 59 & 12 \\
$\geq 175,000$ & 55 & 10 \\
Prefer not to answer & 117 & 23 \\
Location of survey & & \\
Madison River & 69 & 13 \\
Snake River & 19 & 3 \\
Trout Lake & 396 & 76 \\
Yellowstone River & 39 & 8 \\
& & \\
\hline
\end{tabular}

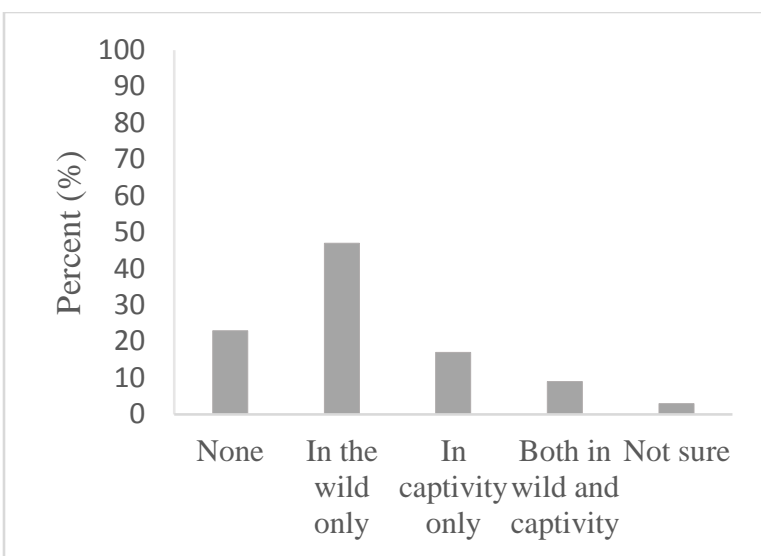

Figure 3. Percent of respondents to the question "Please indicate your previous exposure to the river otter" in our 2015 survey of visitors $(n=517)$ to the Greater Yellowstone Ecosystem. Surveys were conducted from 5 June 2015 to 24 August 2015 at 6 locations throughout the Greater Yellowstone Ecosystem.

\section{$\uparrow \quad$ MANAGEMENT IMPLICATIONS}

This study provides empirical support that exposure to the flagship heightens concern and can lead to the formation of specific conservation intentions.

Specific environmental concerns regarding the river otter and exposure to marketing materials were significant predictors in willingness to engage in pro-conservation behaviors. These findings are consistent with other studies investigating the effects of educational tools focusing on flagship species (e.g., Smith and Sutton 2008). Future research should consider the specific effect of each marketing type to identify the most effective tool in influencing heightened concern for the behavioral intention target.

Direct exposure to the river otter was not a predictive variable in pro-conservation intentions, which counter previous studies which indicated exposure to wildlife increases concern (Skibins and Powell 2013). However, quality of the exposure experience (e.g., time spent watching the species, distance to species) is likely a factor in influencing connection with a species, which was not directly measured in this study, but could be the focus of future research.

Regardless of exposure type, visitors are more likely to spend time to keep local waterways unpolluted and plant trees along local waterways if they knew their contributions would help river otter populations (Figure 4). These results provide empirical evidence that the river otter has the potential to serve as an aquatic flagship for the Greater Yellowstone Ecosystem. 
Table 2. Results of logistic regression analysis, testing for significant effects of exposure types and environmental concern variables on intentions to conserve the river otter and its habitat. Surveys were conducted from 5 June 2015 to 24 August 2015 at 6 locations throughout the Greater Yellowstone Ecosystem.

\begin{tabular}{lccccc}
\hline \multicolumn{1}{c}{ Parameter } & df & $\beta$ & SE & $p$-value & OR $(95 \% \mathrm{CI})$ \\
\hline General ecological intentions & 1 & 0.93 & 0.321 & 0.004 & $2.53(1.34-4.74)$ \\
Otter in wild & 1 & 0.08 & 0.315 & 0.802 & $1.08(.583-2.00)$ \\
Otter in captivity & 1 & 0.19 & 0.322 & 0.546 & $1.22(0.646-2.29)$ \\
Otter in wild and captivity & 1 & 0.12 & 0.51 & 0.812 & $1.23(.497-2.23)$ \\
Marketing material & 1 & 0.63 & 0.304 & 0.02 & $1.87(1.03-3.40)$ \\
Specific environmental concern & 1 & 1.28 & 0.329 & $<0.0005$ & $3.62(1.89-6.9)$ \\
General environmental concern & 1 & 0.79 & 0.342 & 0.02 & $2.20(1.13-4.31)$ \\
\hline
\end{tabular}

$n=306 ;$ Model $x 2=85.92 ; d f=8 ; p=<0.0005 ;$ Overall concordance $=23.2 \%$

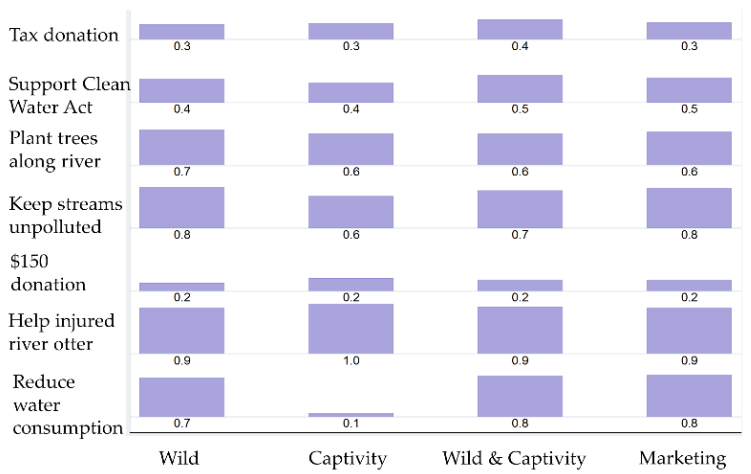

Figure 4. Odd's ratio examining the effects of different types of exposure to river otters (i.e., viewing river otters in wild, in captivity, both in wild and captivity or via marketing materials) on general and specific ecological intentions. Surveys were conducted with visitors $(n=517)$ from 5 June 2015 to 24 August 2015 at 6 locations in the Greater Yellowstone Ecosystem, United States.

\section{ACKNOWLEDGEMENTS}

Support for this study was provided by Frostburg State University. This research would not have been possible without the great assistance of Marie Tosa who helped conduct all the surveys. We would also like to thank Sarah Dewey from GTRE and Stacey Gunther from YELL for permit and logistical assistance, the UW-NPS Research Station for letting us use the kayaks during field research. Our sincere thanks go out to Harold Bergman and Gordo Richman for logistical assistance and great conversations.

\section{$\downarrow \quad$ LiteratURE CITED}

Davis, S.K., J.L. Thompson, and S.E. Schweizer. 2012. Innovations in on-site survey administration using an iPad interface at National Wildlife Refuges and National Parks. Human Dimensions of Wildlife 17:282-294

Dietz, L.A.H., L.A. Dietz, and E.Y. Nagagata. 1994. The effective use of flagship species for the conservation of biodiversity: The example of lion tamarins in Brazil. Pages 32-49 In: P.J.S. Olney, G.M. Mace, and A.T.C. Feistner (eds.). Creative Conservation: Interactive Management of Wild and Captive Mammals. Chapman \& Hall, London, United Kingdom.

Skibins, J.C., R.B. Powell, and J.C. Hallo. 2012. Charisma and conservation: Charismatic megafauna's influence on safari and zoo tourists' pro-conservation behaviors. Biodiversity Conservation 22:4

Skibins, J.C., and R.B. Powell. 2013. Conservation caring: Measuring the influence of zoo visitors' connection to wildlife on proconservation behaviors. Zoo Biology 32:528540.

Smith, A.M., and S.G. Sutton. 2008. The role of a flagship species in the formation of conservation intentions. Human Dimensions of Wildlife 13:127-140 